\title{
Clinical Trial Censoring
}

National Cancer Institute

\section{Source}

National Cancer Institute. Clinical Trial Censoring. NCI Thesaurus. Code C118962.

When information on time-to-event is not available due to loss to follow-up or nonoccurrence of outcome event before the trial end. The data on that participant is banned or removed from the study data. 